\title{
Surveillance Renal Allograft Biopsy on Diagnosis of BK Virus Nephropathy in Chinese Renal Transplant Recipients
}

\author{
Shu-Ming Ji ${ }^{1}$, Zhi-Hong Liu ${ }^{2}$, Di Wu ${ }^{1}$, Ji-Qiu Wen ${ }^{1}$, Ke-Nan Xie ${ }^{1}$, Qi-Quan Sun ${ }^{1}$, Jin-Song Chen ${ }^{1}$ \\ ${ }^{1}$ Research Institute of Nephrology, Department of Nephropathy, Jinling Hospital, Nanjing, China \\ ${ }^{2}$ Nanjing University School of Medicine, Nanjing, China \\ Email: jishuming@medmail.com.cn
}

Received October 7, 2012; revised November 7, 2012; accepted November 14, 2012

\begin{abstract}
Objective: We prospectively investigated 121 renal allograft biopsy specimens performed in our center. Methods: BKVAN was diagnosed by light microscopic examination and a positive immunohistochemistry staining of anti-SV40 large $T$ antibody in a biopsy specimen. Results: Of the 121 patients, nine were diagnosed with BKVAN (7.4\%). Nine patients with BKVN classically presents as allograft dysfunction with an asymptomatic rise in serum creatinine, about 3 to 39 months posttransplant. Urinary decoy cells are positive in two patients $(22.2 \%)$. The histologic changes of BKVN are not pathognomonic, and can be mistaken for allograft rejection, i.e., tubulointerstitial nephritis with varying degrees of inflammatory infiltrates, tubulitis and tubular atrophy, and fibrosis. Typical findings on histology are focal interstitial mononuclear inflammatory cell infiltrates, presence of plasma cells, necrotic tubular epithelium, and presence of homogenous intranuclear inclusion bodies. Immunohistochemistry with SV40 staining were positive in allograft. Graft loss occurred in one patient and the other 8 showed progressive allograft dysfunction. Conclusion: The definitive diagnosis of BKV disease requires renal biopsy. Immunohistochemistry with SV40 staining has been used as an indirect method to document the presence of BKVAN.
\end{abstract}

Keywords: Renal Transplantation; Biopsy; BK Virus; BK Virus Associated Nephropathy; Diagnosis

\section{Introduction}

BK virus associated nephropathy (BKVAN) is one of the most serious complications after renal transplantation $[1,2]$. Most renal transplant recipients with BKVN manifest with renal dysfunction $[3,4]$. In recent years, routine post-transplant protocol biopsy has also detected BKVN in the absence of serum creatinine elevation. Progressive renal failure has been reported in approximately $30 \%$ $60 \%$ of cases. BKVAN has not attracted the attention of clinical transplant physician over the years. With the extensive use of new immunosuppressive agents, the infection ratio of BK virus after renal transplantation continues to rise, currently there are few effective therapeutic drugs and the rates of failure and loss caused by BKVAN are high, and the leading risk factor causing BKVAN and renal allograft loss is not clear, which is a difficult problem in dire need of resolve $[5,6]$. The BKVAN diagnosis mainly depends on the transplant renal biopsy. BK virus can cause acute necrosis of renal tubular epithelia, and early diagnosis of BKVAN and use of effective treatment can prevent irreversible kidney damage caused by virus and improve prognosis of BKVAN, therefore early diagnosis of BKVAN has become current research focus
[7,8]. Celik et al. took the initiative in regular biopsy after renal transplantation, which contributed to timely diagnosis of BKVAN [9]. Currently, there are transplant centers which have begun to carry out some research on BK virus infection after renal transplantation, but clinical and pathological characteristics studies on BKVAN in China have rarely reported and the renal transplantation insufficiency and even renal transplantation loss caused by BKVAN are lack of enough attention. In this paper, 9 cases of patients diagnosed as BKVAN through pathology of transplanted kidney by biopsy in our hospital were studied because of chronic renal allograft dysfunction so as to provide a reference for clinical, pathological and treatment outcomes of patients with BKVAN.

\section{Methods}

\subsection{Objects}

Among 121 cases of subjects confirned with histopathologic biopsies of kidney transplants with decreased graft functions in our unit, from August 2005 to April 2011 period, 9 patients accorded with the inclusion criteria. All subjects have signed informed consent. 


\subsection{Inclusion Criteria}

1) More than 3 months after renal transplantation, increased serum creatinine $(\mathrm{SCr} \geq 1.5 \mathrm{mg} / \mathrm{dl}$ or greater than $30 \%$ in increase of serum creatinine values above the baseline), and slow clinical progression (increase in serum creatinine $<1 \mathrm{mg} /$ week), accompanied with or without hematuria or proteinuria; 2) Vascular and post-renal factors were excluded by color doppler ultrasound of patients with transplanted kidney. All patients were carried out with blood routine, urine routine, liver and kidney function, blood coagulation function and concentration measurements of cyclosporine A (CsA ) or FK506 (tacrolimus, Tac) and mycophenolate mofetil (MMF) in blood before biopsy. Decoy cells were detected in urine. All patients gave their written informed consent.

\subsection{Pathological Diagnosis of Renal Graft Biopsy}

Renal graft biopsy was carried out under the guidance of $\mathrm{B}$ ultrasound. The specimens were qualified if the renal tissues contained 2 vessels and more than 10 renal glomeruluses, and were confirmed with conventional light microscopy and immunofluorescence examination. Lightmicroscopic staining included HE, PAS, PASM and Masson trichrome staining. The pathological diagnosis of transplanted kidney can accord with Banff 97 criteria [10].

\subsection{Main Outcome Measueres}

Immunofluorescence. Direct fluoreslent assay was used to observe the deposition intensities and sites of $\operatorname{IgG}, \operatorname{IgA}$, $\mathrm{IgM}, \mathrm{C} 3, \mathrm{C} 4, \mathrm{C} 1 \mathrm{q}$, and $\mathrm{C} 4 \mathrm{~d}$. All frozen tissue sections were confirmed with $\mathrm{C} 4 \mathrm{~d}$ immunofluorescence staining, and the staining intensities were in accordance with Banff 2001 criteria, in whith C4d negative was defined as $<25 \%$ of PTC C4d deposition, reversible focal positive was defined as $25 \%$ to $50 \%$ of PTC C4d deposition and $\mathrm{C} 4 \mathrm{~d}$ asystematic positive was defined as $>50 \%$ of PTC C4d deposition [11].

Immunohistochemistry. Enrolled patients were carried out with CD4, CD8, CD68, HLA-DR and BK virus immunohistochemical staining. Paraffin immunohistochemistry and Envision two-step method were applied: the paraffin sections were deparaffinized by normal method, treated by $3 \%$ hydrogen peroxide to inhibit the endogenous peroxidase, placed into a pressure cooker with $1 \mathrm{ml}$ EDTA solution for antigen retrieval, blocked in normal $10 \%$ bull serum solution, washed and added with monoclonal mouse anti-human CD3 (1:100), CD68 (1:100), CD20 antibody (1:100) and HLA-DR antibody (1:50), respectively, incubated at room temperature for 2 $\mathrm{h}$, added with Envision and incubated at room temperature for $40 \mathrm{~min}$, colored with $\mathrm{DAB}$ for $5 \mathrm{~min}$, counter- stained with hematoxylin for $2 \mathrm{~min}$, dried and sealed with neutral gum. Read under a Nikon 8100 microscope. SV240 large T antigen was used for positioning (antipolyomavirus antibody staining).

The infiltration degrees of CD4, CD8, and CD68positive cells were classified according to the following criteria: 16 high power fields with a total area of $1 \mathrm{~mm}^{2}$ were randomly selected for counting, the sum of counting $>300$ was defined as 3 points, 200 - 300 was defined as 2 points, 100 - 200 was defined as 1 point, and $<100$ was defined as 0 point.

HLA-DR expression was judged on the basis of 50 tubular cross-sections, HLA-DR positive tubular accounted for a percentage of the whole tubular. $>50 \%$ was defined as 3 points, $25 \%$ - 50\% was defined as 2 points, $10 \%$ - $25 \%$ was defined as 1 point, and $<10 \%$ was defined as 0 point.

\subsection{Criteria of BK Virus-Associated Nephropathy $[12,13]$}

SV240 large T antigen was located in the nuclear of renal tubular epithelial cell. Positive expression was brown and negative cells were not detected. BKVAN was diagnosed through their positive expression in combination with $\mathrm{HE}$ staining.

\subsection{Statistical Analysis}

The measurement data is represented by mean \pm standard deviation $(\mathrm{x} \pm \mathrm{s}), \mathrm{P}<0.05$ has significant difference, $\mathrm{P}<$ 0.01 has obviously significant difference.

\section{Results}

\subsection{Clinical Data}

Renal allograft biopsy was implemented in 121 patients followed by $\mathrm{BKV}$ large $\mathrm{T}$ antigen staining, 9 positive cases were found and diagnosed as BKVAN with incidence rate of $7.4 \%$. According to staining results of BKV large $\mathrm{T}$ antigen staining of renal allograft biopsy, the patients were divided into two groups: BKVAN group (n $=9)$ and non-BKVAN group $(\mathrm{n}=112)$. There was no significant difference in gender, age, tissue matching, postoperative acute rejection, and serum creatinine levels when renal biopsy (Table 1). But the incidences of pulmonary infection, FK506 renal toxicity, and chronic renal allograft insufficiency before biopsy in BKVAN group were obviously higher than that in non-BKVAN group. 9 patients all had slowly progressive increase in serum creatinine at the onset of disease, without hematuria and proteinuria, and other specific clinical symptoms.

Decoy cells were found in urine of 2 patients (positive rate of $22.2 \%$ ), and Decoy cells in urine were detected for 3 times, and the results showed that there were a large 
Table 1. Comparison between BKVAN and non-BKVAN groups.

\begin{tabular}{|c|c|c|c|}
\hline & $\begin{array}{l}\text { BKVAN } \\
\text { group }\end{array}$ & $\begin{array}{l}\text { Non-BKVAN } \\
\text { group }\end{array}$ & $\mathrm{P}$ value \\
\hline Gender (F/M) & $6 / 3$ & $75 / 37$ & NS \\
\hline Age (years) & $36.8 \pm 10.1$ & $37.4 \pm 11.2$ & NS \\
\hline $\begin{array}{l}\text { Postoperative onset time } \\
\text { (months) }\end{array}$ & $9.25 \pm 3.66$ & $11.4 \pm 5.63$ & NS \\
\hline \multicolumn{4}{|c|}{ Historical events } \\
\hline Acute rejection & $1(12.5 \%)$ & $14(12.5 \%)$ & NS \\
\hline Pneumonia & $3(37.5 \%)$ & $13(11.6 \%)$ & $<0.05$ \\
\hline FK506 nephrotoxicity & $2(22.2 \%)$ & $10(8.9 \%)$ & $<0.05$ \\
\hline \multicolumn{4}{|c|}{ Immunosuppressive schema } \\
\hline $\mathrm{CsA}+\mathrm{MMF}+$ Pred $(\mathrm{CMP})$ & $1(11.1 \%)$ & $13(11.6 \%)$ & NS \\
\hline $\mathrm{Tac}+\mathrm{MMF}+$ Pred $(\mathrm{TMP})$ & $7(77.8 \%)$ & $99(88.4 \%)$ & NS \\
\hline $\begin{array}{c}\mathrm{Tac}+\mathrm{MMF}+\text { Pred }+ \text { TII } \\
(\mathrm{TMPT})\end{array}$ & $1(11.1 \%)$ & 0 & \\
\hline \multicolumn{4}{|c|}{ Serum creatinine level } \\
\hline atrenal biopsy (mg/dl) & $2.7 \pm 1.5$ & $2.5 \pm 1.2$ & NS \\
\hline
\end{tabular}

number of visible exfoliated cells and scattered BKVpositive cells. Green fluorescence can be visible in the cell nuclear (Figures 1(a) and (b)). The results are as follows: urinary protein $<0.10 \mathrm{~g} / 24$ hour, urinary sediment $\mathrm{RBC}<10000.0 / \mathrm{ml}$, white blood cells $<0-1 / \mathrm{HP}$; $\mathrm{NAG}$ enzyme $>42.1 \mathrm{U} / \mathrm{g} \cdot \mathrm{Cr}(<17.0 \mathrm{U} / \mathrm{g} \cdot \mathrm{Cr}), \mathrm{RBP}>$ $11.94 \mathrm{mg} / \mathrm{L}, \mathrm{KIM}-1>11.46 \mu \mathrm{g} / \mathrm{L}(<0.4 \mu \mathrm{g} / \mathrm{L}), \mathrm{IL}-18$ $22.93 \mathrm{ng} / \mathrm{L}(<20 \mathrm{ng} / \mathrm{L})$, and NGAL $>25.18 \mu \mathrm{g} / \mathrm{L}(<20$ $\mu \mathrm{g} / \mathrm{L})$.

\subsection{Pathological Features of BKVAN}

The typical pathological features of BKVAN are as follows: different phenotypes of basophilic BK virus inclusion bodies appeared renal tubular epithelial cells, infected renal tubular epithelial cells exfoliated towards renal tubular lumen, resulting in bare spot on the base membrane (Figures 2(a) and (b)). Interstitial prominent presented as multifocal gathered infiltrating cells, with mononuclear cells and plasma cells as main, and their surrounding tubulars often had tubulitis, multifocal thickening and atrophy of tubular basement membrane (Figures 2(c) and (d)). Later pathological changes mainly include fibrosis, with a few of BKV-infected cells (Figure 2(d)).

Immunofluorescence: Immunofluorescence of $\mathrm{IgG}$, $\operatorname{IgM}, \operatorname{Ig} \mathrm{A}, \mathrm{C} 3, \mathrm{C} 4, \mathrm{C} 1 \mathrm{q}$, and $\mathrm{C} 4 \mathrm{~d}$ were negative.

Immunohistochemistry: A large aggregation of $\mathrm{CD} 3$, CD4, CD8, CD68 positive cells, CD3 $809 \pm 201 / \mathrm{mm}^{2}$, CD4 $348 \pm 110 / \mathrm{mm}^{2}$, CD8 $295 \pm 89 / \mathrm{mm}^{2}$, and CD68 $679.5 \pm 209 / \mathrm{mm}^{2}$, can be seen in renal interstitial from all

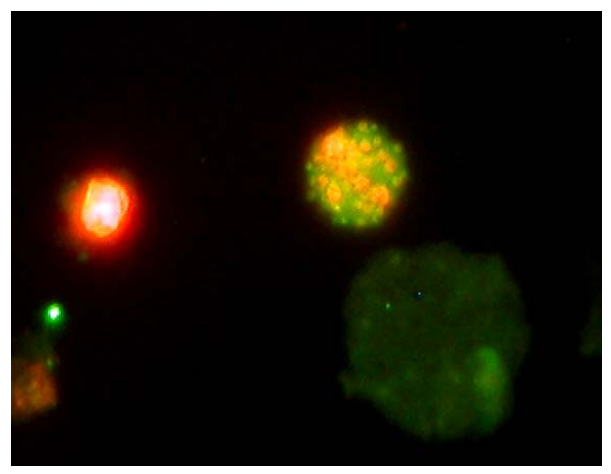

(a)

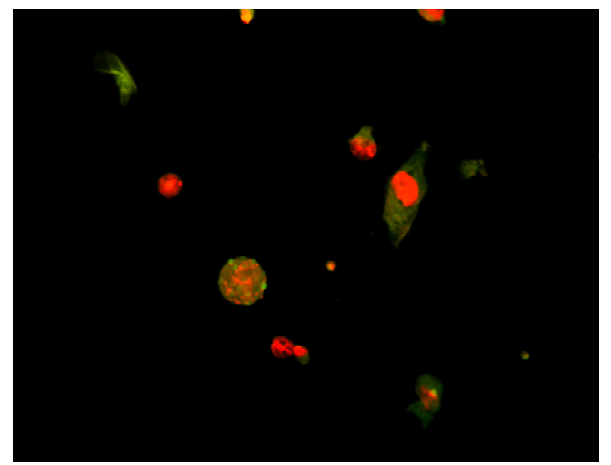

(b)

Figure 1. Decoy cells in urine (indirect IF, ×400).

renal pathology. In one patient combined with rejection, HLA-DR and high IL-2R expression were $19.6 \%$ and $148 / \mathrm{mm}^{2}$, respectively; in patients combined without rejection, HLA-DR and IL-2R expression were mostly less than 5\%. 9 patients were implemented with SV-40 large $\mathrm{T}$ antigen staining of renal tissues, positive scattered BKV tubules can be seen in renal cortex and medulla, that is the nuclear of tubular epithelial cells was brown, the middle was transparent, and the peripheral was burr-like, and exfoliated cell BKV expression can be seen in lumen of renal tubules (Figures 3(a) and (b)).

Ultrastructural characteristics of polyoma virus inclusion body: Under electron microscopy, virus-like particles arranged in dense crystalline with a diameter of 40 - $45 \mathrm{~nm}$ can be seen in renal tubular epithelial cells or endothelial cells (Figures 4(a) and (b)).

\subsection{Concentration of Immunosuppressant and BKVAN}

Nine patients were carried out with three-point MPA AUC $0-12$ examination when biopsy, and the results showed significantly higher than patients who were not infected with BKV, $75.85 \pm 20.49(51.04-96.33) \mathrm{mg} \cdot \mathrm{h} / \mathrm{L}$ vs. $36.3 \pm 11.9(34.5-55.1) \mathrm{mg} \cdot \mathrm{h} / \mathrm{L}$, respectively. FK506 trough concentrations were also significantly higher than that in control group, $9.28 \pm 2.38(9.8-11.05) \mathrm{ug} / \mathrm{L}$ vs. $5.95 \pm 1.14(5.6-7.2) \mathrm{ug} / \mathrm{L}$. 


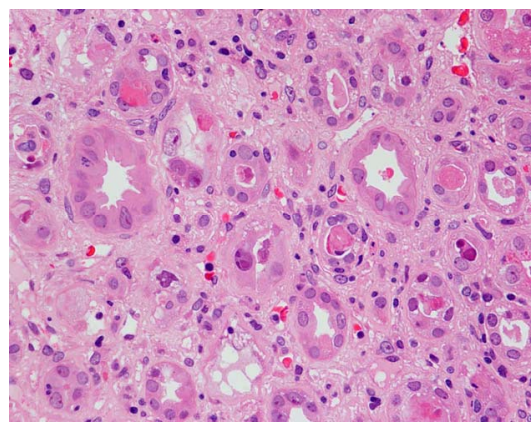

(a)

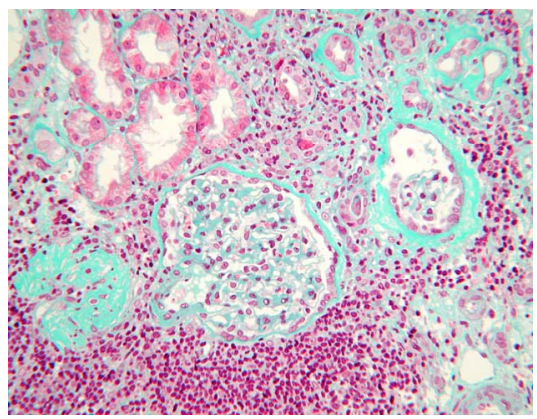

(c)

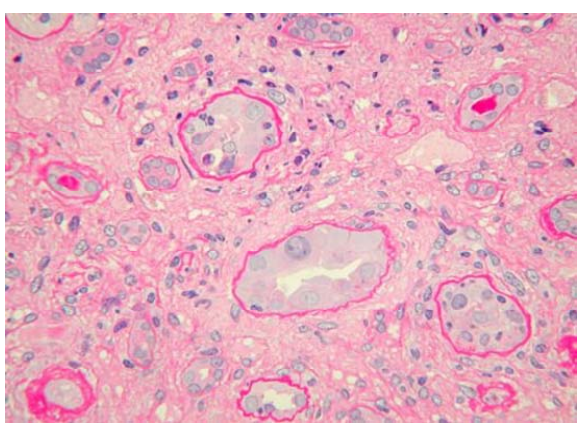

(b)

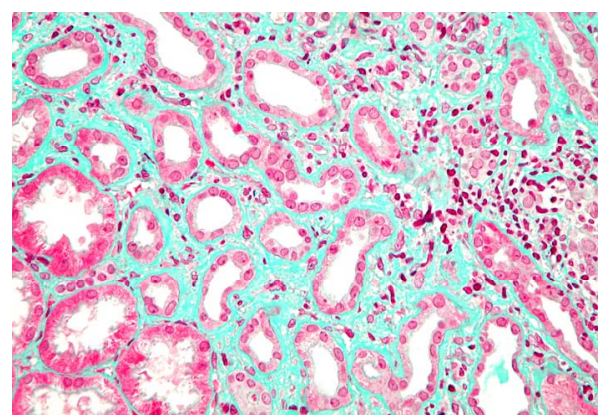

(d)

Figure 2. Pathological features of BKVAN.

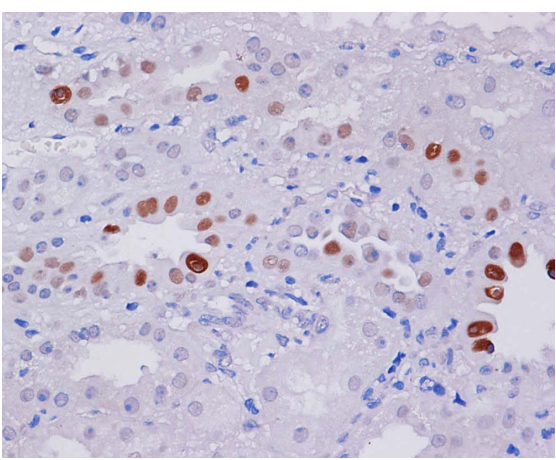

(a)

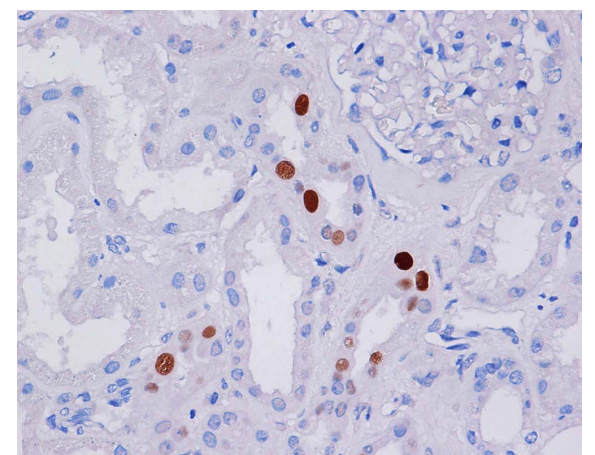

(b)

Figure 3. BKV test in frozen section of renal tissues $(\mathrm{IH}, \times 400)$.

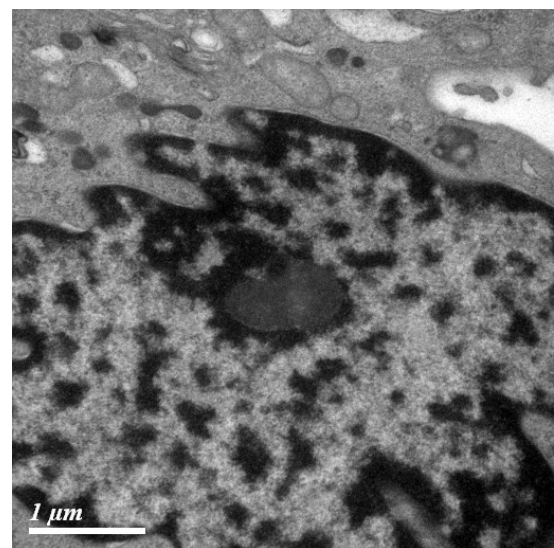

(a)

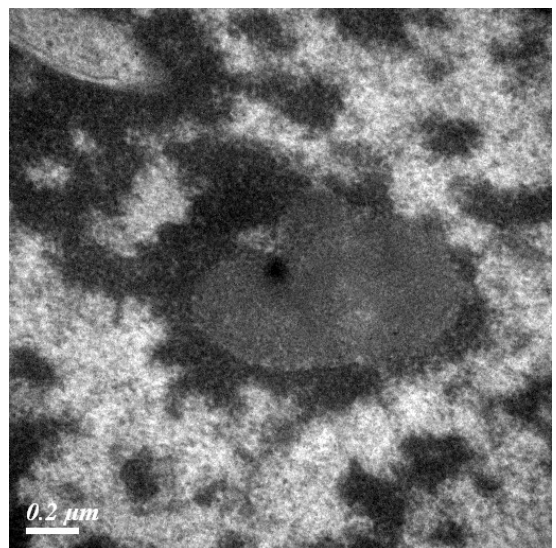

(b)

Figure 4. BKVAN ultrastructural changes. 


\subsection{BKVAN Follow-Up Treatment}

After 9 patients were diagnosed as BKVAN, FK506 was reduced, triptolide and MMF were stopped and converted to leflunomide $(10-40 \mathrm{mg} / \mathrm{d})$ to maintain the therapy. The longest follow-up was 5 years and the shortest was 6 months, average follow-up of $26.60 \pm 13.76$ months. The function of transplanted kidney was stable and serum creatinine was remained at $1.46-4.57 \mathrm{mg} / \mathrm{dl}$, but the serum creatinine levels in most patients can not be reduced to the level before onset. There were 1 case of renal transplantation loss, 3 cases of improved, 2 cases of stable, and 3 cases of deteriorated, and the average serum creatinine doubling time was longer than $22.4 \pm 15.60$ months. There was no death during the whole follow-up.

\section{Discussion}

BKVAN is a group of diseases paid attention gradually and is continuously reported on a global scale. The incidences of PVAN reported by various transplant centers were $2 \%$ to $9.3 \%$ [14]. It was reported that progressive renal failure occurred in $30 \%$ to $60 \%$ of patients, of which $45 \%$ of the patients developed to irreversible renal failure. In the data of this group, 121 patients underwent BKV large $T$ antigen staining and it was found that 9 patients were positively diagnosed as BKVAN, with positive rate of $7.4 \%$, which was similar with the related reported international incidence.

The study found that BKVAN mostly occurred in the period of 3 to 13 months after renal transplantation, average of 10 months. There was no characteristical symptoms in clinical, and asymptomatic elevated serum creatinine were often seen as the main features, accompanied by urine detection indicators caused by renal tubular damage, such as increase in urinary NAG enzyme and urine RPB protein levels. Decoy cells can be found in urine in this group, with positive rate of $22.2 \%$, and we found that other reasons, such as adenovirus infection, also can cause positive decoy cell in urine, because the urinary exfoliated cells had variations in the number and morphology. Therefore, the specificity of this test was lower and can be used as screening index for BKVAN patients [15-17]. Why BKVAN patients mainly acted as renal tubular injury without proteinuria and erythrocyturia still needs further study. The above situations were mainly caused because BK virus can lie in the renal tubular epithelial cells and urinary transitional epithelial cells after BK virus latent infection and reproduce in a large number and damage renal tubular when the host immunity were declined $[12,18,19]$.

The diagnosis of BKVAN needed to be established on the basis of renal allograft biopsy [20,21], and the typical pathology mainly presented as different phenotypes of basophilic BK virus inclusion bodies occurred in the nu- clear of renal tubular epithelial cells, infected renal tubular epithelial cells exfoliated towards renal tubular lumen, resulting in bare spot on the base membrane (Figures 2(a) and (b)). Interstitial prominent presented as multifocal gathered infiltrating cells, with mononuclear cells and plasma cells as main, and their surrounding tubulars often had tubulitis, multifocal thickening and atrophy of tubular basement membrane (Figures 2(c) and (d)). Parts of pathological changes took fibrosis as main, only a small number of BKV-infected cells. 9 cases of patients with BKVAN were confirmed by electron microscopy, and the electron microscopy showed that virus-like particles arranged in dense crystalline with a diameter of 40 $45 \mathrm{~nm}$ can be seen in renal tubular epithelial cells or endothelial cells. According to morphological changes, inflammatory cell infiltration, tubular atrophy and interstitial fibrosis, Hirsch et al. [9] divided the pathological process of BKVAN into three phases through semi-quantitative evaluation: Phase I: mild pathological changes, such as positive stained large $T$ antigen of focal tubular epithelial cells and virus inclusion bodies, no extensive necrosis and inflammatory infiltration can be seen. Phase II: extensive multifocal diffuse pathological changes of cells, necrosis associated with inflammatory response and initial signs of interstitial fibrosis can be seen. Infiltrated inflammatory cells included polymer-phonuclear cells, monocytes and plasma cells. Phase III: renal interstitial fibrosis, scarring and even calcification can be seen. BKVAN observed in this study was mainly Phase II. Therefore, it has extremely important clinical significance for patients with renal allograft dysfunction to carry out renal allograft biopsy for detecting BKVAN in early phase and staging.

Nine patients had obviously abnormal renal function in case of biopsy. One patient was initially diagnosed as acute rejection. As the early pathological features of BKVAN often similar to the performance of interstitial nephritis, it was difficult to distinguish from acute rejection only through routine staining and light microscopy, especially for mild rejection. Therefore, it becomes necessary for using immune staining on the basis of light microscopy. In this study, kidney tissue SV-40 large T antigen staining was used, which has advantage of specificity. Immunohistochemical staining of transplanted kidney SV-40 large $T$ antigen was widely recognized "gold standard" for the diagnosis of BKVAN [22]. 9 patients were implemented with SV-40 large T antigen staining of renal tissues, positive scattered BKV tubules can be seen in renal cortex and medulla, that is the nuclear of tubular epithelial cells was brown, the middle was transparent, and the peripheral was burr-like, and exfoliated cell BKV expression can be seen in lumen of renal tubules (Figures 3(a) and (b)). In addition, the acute rejection combined with BKVAN also should be discrimi- 
nated from the secondary interstitial non-specific changes by virus, because under the high load conditions, serious viral infection often can lead to renal tubular epithelial cell necrosis, polymorphonuclear leukocyte infiltration and plasma cells, which could also lead to higher rate of misdiagnosis of this disease. It is interesting to find that all kidney immunofluorescence IgG, IgM, IgA, C3, C4, $\mathrm{C} 1 \mathrm{q}$, and $\mathrm{C} 4 \mathrm{~d}$ staining were negative, a large aggregation of CD3, CD4, CD8, CD68 positive cells, CD3 $809 \pm$ $201 / \mathrm{mm}^{2}$, CD4 $348 \pm 110 / \mathrm{mm}^{2}$, CD8 $295 \pm 89 / \mathrm{mm}^{2}$, and CD68 $679.5 \pm 209 / \mathrm{mm}^{2}$, can be seen in renal interstitial from all renal pathology. In one patient combined with rejection, HLA-DR and high IL-2R expression were $19.6 \%$ and $148 / \mathrm{mm}^{2}$, respectively; in patients combined without rejection, HLA-DR and IL-2R expression were mostly less than 5\%. Therefore, the transplanted kidney tissue HLA-DR, IL-2R expression and C4d staining to identify BKVAN and is an important indicator of acute rejection [23]. Therefore, HLA-DR, IL-2R expression in the transplanted kidney tissues and $\mathrm{C} 4 \mathrm{~d}$ staining were important indicators for identify BKVAN and acute rejection [23].

It is reported that long-term high-dose application of FK506, MMF and other immunosuppressive agents can promote BK viral replication [24,25]. Multiple transplant centers revealed that after previous $\mathrm{CsA}+$ azathioprine (Aza) immunosuppressive regimen was transferred to FK506 and MMF, the BKN incidence increased significantly. Large doses of FK506 (whole blood concentration of $8 \mathrm{ug} / \mathrm{L}$ ) or MMF can increase the incidence of BKVAN by 13 times. The results of a prospective study showed that the incidence rate of BKVAN in patients with transplanted kidney who accepted FK506 or MMFbased immunosuppressive therapy was about $5 \%$. Therefore, FK506 or MMF-based treatment programs have the risk of increasing BKN. In this study, except for 1 patient with $\mathrm{CsA}+\mathrm{MMF}+$ Pred, the remaining patients were administrated with immunosuppressive regimen of FK506 combined with MMF, and the blood concentration of FK506 and MPA were significantly higher than that in the control group. Whether FK506 and MPA concentrations are risk factors still needs further large sample of clinical observation. However, BK virus infection was not associated with the application of particular immunosuppressant, more likelym it was related to the overall state of over-immunosuppression.

Although for the treatment of BKVAN, it is reported [26-28] that cidofovir and laifumite can be effectively used for antiviral treatment, it is still a lack of accepted, standard treatment. Reduction of immunosuppressive agents is the core principle of treatment [9]: for all patients diagnosed as BKVAN, the dosage of FK506 was lowered, mycophenolate mofetil was stopped and converted to low dose of laifumite. The longest follow-up was 5 years and the shortest was 6 months, average follow-up of $26.60 \pm 13.76$ months. The function of transplanted kidney was stable and serum creatinine was remained at $1.46-4.57 \mathrm{mg} / \mathrm{dl}$, but the serum creatinine levels in most patients can not be reduced to the level before onset. There were 1 case of renal transplantation loss, 3 cases of improved, 2 cases of stable, and 3 cases of deteriorated, and the average serum creatinine doubling time was longer than $22.4 \pm 15.60$ months. There was no death during the whole follow-up. The long-term effect of laifumite in the treatment of patients with BKVAN still needs further observation.

\section{Conclusion}

High-dose immunosuppression or immune dysfunction is the main reason for the occurrence BKVAN. BKVAN patients are characterized by slowly progressive increase in serum creatinine companied by increased tubular injury index in clinical. BKVAN diagnosis mainly depends on the transplant renal biopsy pathology, and using SV40 large $\mathrm{T}$ antigen staining and electron microscopy can improve the diagnostic rate of BKVAN and the detections of C4d, IL-2R and HLA-DR antigen of transplanted kidney tissues are extremely important for identification and diagnosis of BKVAN. Laifumite can effectively control most of the lesions progress, but its long-term effect needs further observation.

\section{REFERENCES}

[1] S. M. Ji and Z. Tang, "Polyomavirus-Associated Nephropathy after Renal Allograft," Chinese Journal of Nephrology Dialysis \& Transplantation, Vol. 15, No. 6, 2006, pp. 572-578.

[2] P. S. Randhawa and A. J. Demetris, "Nephropathy Due to Polyomavirus Type BK," New England Journal of Medicine, Vol. 342, 2000, p. 1361. doi:10.1056/NEJM200005043421809

[3] S. Hussain, B. A. Bresnahan, E. P. Cohen, et al., "Rapid Kidney Allograft Failure in Patients with Polyoma Virus Nephritis with Prior Treatment with Antilymphocyte Agents," Clinical Transplantation, Vol. 16, 2002, pp. 4347. doi:10.1034/j.1399-0012.2002.00075.x

[4] H. H. Hirsch, "Polyomavirus BK Nephropathy: A (Re-) Emerging Complication in Renal Transplantation," American Journal of Transplantation, Vol. 2, 2002, p. 25. doi:10.1034/j.1600-6143.2002.020106.x

[5] M. Mengel, M. Marwedel, J. Radermacher, et al., "Incidence of Polyomavirus Nephropathy in Renal Allografts: Influence of Modern Immunosuppressive Drugs," $\mathrm{Ne}$ phrology Dialysis Transplantation, Vol. 18, 2003, p. 1190. doi:10.1093/ndt/gfg072

[6] M. S. Sachdeva, R. Nada, V. Jha, et al., "The High Incidence of BK Polyoma Virus Infection among Renal Transplant Recipients in India," Transplantation, Vol. 77, 
2004, p. 429. doi:10.1097/01.TP.0000113163.02039.30

[7] R. John and A. M. Herzenberg, "Our Approach to a Renal Transplant Biopsy," Journal of Clinical Pathology, Vol. 63, No. 1, 2010, pp. 26-37. doi:10.1136/jcp.2009.067983

[8] M. Ahuja, E. P. Cohen, A. M. Dayer, et al., "Polyoma Virus Infection after Renal Transplantation. Use of Immunostaining as a Guide to Diagnosis," Transplantation, Vol. 71, 2001, pp. 896-899. doi:10.1097/00007890-200104150-00013

[9] B. Celik, R. Shapiro, A. Vats, et al., "Polyomavirus Allograft Nephropathy: Sequential Assessment of Histologic Viral Load, Tubulitis and Graft Function Following Changes in Immunosuppression," American Journal of Transplantation, Vol. 3, No. 11, 2003, pp. 1378-1382. doi:10.1046/j.1600-6135.2003.00238.x

[10] L. C. Racusen, K. Solez, R. B. Colvin, et al., "The Banff 97 Working Classification of Renal Allograft Pathology," Kidney International, Vol. 55, No. 2, 1999, pp. 713-723. doi:10.1046/j.1523-1755.1999.00299.x

[11] G. A. Bǒhmig, M. Exner, A. Habicht, et al., "Capillary C4d Deposition in Kidney Allografts: A Specific Marker of Alloantibody-Dependent Graft Injury," Journal of the American Society of Nephrology, Vol. 13, 2002, pp. 1091-1099.

[12] S. Hariharan, "BK Virus Nephritis after Renal Transplantation," Kidney International, Vol. 69, 2006, pp. 655-662. doi:10.1038/sj.ki.5000040

[13] H. P. Chen, Z. H. Liu and L. S. Zeng, "PolyomavirusAssociated Nephropathy," Chinese Journal of Nephrology Dialysis \& Transplantation, Vol. 16, No. 4, 2007, pp. 389-393.

[14] Y. Namba, T. Moriyama, M. Kyo, et al., "Prevalence, Characteristics, and Outcome of BK Virus Nephropathy in Japanese Renal Transplant Patients: Analysis in Protocol and Episode Biopsies," Clinical Transplantation, Vol. 19, 2005, pp. 97-101. doi:10.1111/j.1399-0012.2004.00305.x

[15] H. H. Hirsch, W. Knowles, M. Dickenmann, et al., "Prospective Study of Polyomavirus Type BK Replication and Nephropathy in Renal-Transplant Recipients," New England Journal of Medicine, Vol. 347, 2002, pp. 488-496. doi:10.1056/NEJMoa020439

[16] C. B. Drachenberg, C. O. Beskow, C. B. Cangro, et al., "Human Polyoma Virus in Renal Allograft Biopsies: Morphological Findings and Correlation with Urine Cytology," Human Pathology, Vol. 30, 1999, pp. 970-977. doi:10.1016/S0046-8177(99)90252-6

[17] G. A. Weinberg and A. N. Mian, "BK Virus Nephropathy and Other Polyoma Virus Infections," The Pediatric Infectious Disease Journal, Vol. 29, 2010, pp. 257-260. doi:10.1097/INF.0b013e3181d01c6d

[18] D. Adhania, C. Snopkowski, R. Ding, et al., "Validation of Noninvasive Diagnosis of BK Virus Nephropathy and Identification of Prognostic Biomarkers," Transplantation, Vol. 90, 2010, pp. 189-197. doi:10.1097/TP.0b013e3181e2a932

[19] J. E. Greenlee, S. H. Clawson, R. C. Pheleps and W. G. Stroop, "Distribution of K-Papovavirus in Infected Newborn Mice," Journal of Comparative Pathology, Vol. 111, 1994, pp. 259-268. doi:10.1016/S0021-9975(05)80004-0

[20] C. B. Drachenberg, J. C. Papadimitriou, H. H. Hirsch, et al., "Histological Patterns of Polyomavirus Nephropathy: Correlation with Graft Outcome and Viral Load," American Journal of Transplantation, Vol. 4, 2004, pp. 2082 2092. doi:10.1046/j.1600-6143.2004.00603.x

[21] B. H. H. Chung, Y. A. Hong, H. G. Kim, et al., "Clinical Usefulness of BK Virus Plasma Quantitative PCR to Prevent BK Virus Associated Nephropathy," Transplant International A 2012 European Society for Organ Transplantation, Vol. 25, 2012, pp. 687-695.

[22] V. Nickeleit, H. H. Hirsch, M. Zeiler, et al., "BK Virus Nephropathy in Renal Transplants-Tubular Necrosis, MHC-Class II Expression and Rejection in a Puzzling Game," Nephrology Dialysis Transplantation, Vol. 15, 2000, pp. 324-332. doi:10.1093/ndt/15.3.324

[23] S. M. Ji, L. S. Li, H. P. Chen et al., "Re-Evaluation of Soluble Interleukin-2 Receptor Used in the Diagnosis of Acute Rejection," Chinese Journal of Nephrology Dialysis \& Transplantation, Vol. 5, No. 2, 1996, pp. 17-20.

[24] D. C. Brennan, I. Agha, D. I. Bohl, et al., "Incidence of BK with Tacrolimus versus Cyclosporine and Impact of Preemptive Immunosuppression Reduction," American Journal of Transplantation, Vol. 5, 2005, pp. 582-594. doi:10.1111/j.1600-6143.2005.00742.x

[25] A. S. Weiss, J. Gralla, L. Chan, et al., "Aggressive Immunosuppression Minimization Reduces Graft Loss Following Diagnosis of BK Virus-Associated Nephropathy: A Comparison of Two Reduction Strategies," Clinical Journal of the American Society of Nephrology, Vol. 3, 2008, pp. 1812-1819. doi:10.2215/CJN.05691207

[26] R. Rahamimov, S. Lustig, A. Tovar, et al., "BK Polyoma Virus Nephropathy in Kidney Transplant Recipient: The Role of New Immunosuppressive Agents," Transplantation Proceedings, Vol. 35, 2003, pp. 604-605. doi:10.1016/S0041-1345(03)00006-X

[27] P. V. Kadambi, M. A. Josephson, J. Williams, et al., "Treatment of Refractory BK Virus-Associated Nephropathy with Cidofovir," American Journal of Transplantation, Vol. 3, 2003, pp. 186-191. doi:10.1034/j.1600-6143.2003.30202.x

[28] M. A. Josephson, D. Gillen, B. Javaid, et al., "Treatment of Renal Allograft Polyoma BK Virus Infection with Leflunomide," Transplantation, Vol. 81, 2006, pp. 704-710. doi:10.1097/01.tp.0000181149.76113.50 